\title{
Parameters Associated with Elevated Systolic Blood Pressure Levels in Greek Military Pilots
}

\author{
G. Platsas ${ }^{1, *}$, G. Kourianidis ${ }^{2}$, P. Toutouzas ${ }^{3}$, C. Stefanadis ${ }^{3}$ and G. Vyssoulis ${ }^{3}$ \\ ${ }^{1}$ Greek Military Academy (SSE), Athens, Greece; ${ }^{2}$ Hellenic Airforce 251 General Hospital, Athens, Greece; \\ ${ }^{3}$ Kapodestrian University of Athens, Athens, Greece
}

\begin{abstract}
Background: Elevated blood pressure levels (BP) continue to comprise one of the most important public health problems worldwide. Hypertension is among the most serious risk factors that relates to myocardial infarction, stroke and kidney failure. The purpose of the study was to examine factors that may contribute to presentation of hypertension in military jet pilots. Methods: This is a cross-sectional study of 300 jet pilots of Greek Air-Force. Several data were retrieved from medical files. Participants filled in a questionnaire about demographics, dietary habits and lifestyle factors. Arterial BP was also measured. Spearman's $r$ was used for correlations. Also, multivariate linear regression analysis was performed. Results: All pilots presented systolic and diastolic BP within normal range (mean: $117.5 \mathrm{mmHg}$ and 77.0 $\mathrm{mmHg}$, respectively). 200 pilots presented optimal BP, 80 normal BP and 20 had marginally normal BP. Most pilots were exercising up to two times weekly $(66.9 \%)$, however, some reported they didn't exercise at all $(12 \%)$ and mentioned exercising for a mean period of $12.0( \pm 7.6)$ years, mainly $(62.1 \%)$ outdoors with aerobic $(52.4 \%)$, anaerobic exercises $(5.6 \%)$ or both $(42 \%)$. Factors that influenced systolic BP levels were body mass index, flight hours, HDL values and exercise intensity. Conclusion: Pilots' medical monitoring seems adequate since there weren't any abnormal BP values. Emphasis should be placed on the continuation of programs already in place with further refinement according to specific needs. Smoking cessation interventions are needed as well as promotion of measures that can effectively lead to long standing life-style changes and dietary modifications.
\end{abstract}

Keywords: Arterial hypertension, flight hours, jet pilots, leisure time physical activity, risk factors.

\section{INTRODUCTION}

Several studies in developed countries in Europe, USA, Canada and Australia have shown that almost one in four adults (25\%) presents hypertension. Prevalence in Greece, varies, according to several epidemiological studies, from $28.4 \%$ to $69.1 \%[1,2]$. It is estimated that hypertensives could be more than 2,000,000 in Greece. The ATTICA study $[3,4]$ has revealed that blood pressure (BP) is associated with physical activity. Among 2282 participants, hypertension prevalence was $36.6 \%$ in men and 5 years following initial measurements, the prevalence rose to $46.5 \%$ in men. In another study (CARDIO 2000) the prevalence of hypertension in men was $44 \%$ [5]. In a multicentre study (EPIC, European Prospective Investigation into Cancer and nutrition) which began in 1994, it was found that in Greece, $40.2 \%$ of men suffered from hypertension. Prevalence was positively associated with age, residence in rural areas and low educational level [6].

Exposure to usual commercial flight conditions has been shown to affect BP levels. During flight, cabin pressure is equivalent to an altitude of 1524-2438 meters (reduced oxygen $(15 \%)$ and reduced atmospheric pressure) [7]. Under these conditions, BP has been found to rise in known hypertensives [8]. However, these conditions differ from fighter

*Address correspondence to this author at the 38 Glinou street, 16345 Ilioupoli, Athens, Greece; Tel: +30 210 9705296; Fax: +30 2310 821795;

E-mail: gplats73@gmail.com jets, where pilots wear anti-stress suits and have undergone special training to counteract effects of g-forces from acceleration, deceleration and flight maneuvers. On the one hand, one could expect that pilots, like the rest of the population, would present similar trends of blood pressure levels and hypertension, however, on the other hand, it is hypothesized that because of job's specific demands, BP levels should be lower. Previous studies on pilots have shown that BP levels don't present significant change over time [9-11]. The present study was performed to investigate whether Greek airforce pilots had similar to the general population BP levels and reveal any contributing factors associated with raised $\mathrm{BP}$ levels.

\section{METHODS}

\section{Study Sample}

In the current study, 300 air-force pilots who were flying jet aircrafts were randomly selected from the population of active fighter jet pilots. Participants were between the age of 25 and 55 years old.

\section{Design and Procedures}

This is a cross sectional study. Data were collected following permission from the Ministry of National Defense. All participants were informed about the aim of the study and signed an inform consent prior to taking part in the study, while they were assured about their anonymity and confidentiality. Pilots filled in a questionnaire regarding their 
dietary habits, lifestyle and exercise information, along with epidemiological data, at their first visit at the military clinic. The questionnaire has been used in a prior epidemiological study about the prevention of coronary disease [5] and was modified to conform to restrictions posed by the military authorities for confidentiality reasons.

Participants were requested to attend a military clinic for five consecutive weeks. Each week, three blood pressure measurements took place using a mercury sphygmomanometer by the same researcher, according to standard guidelines [12]. Measurements of the first visit were not taken into account as well as the first measurement in each subsequent visit. All other measurements were examined and the mean value has been used in all analyses. Participants were instructed not to smoke at least 15 minutes and not to consume caffeinated beverages at least 1 hour prior to BP measurements. They were also asked orally whether they had taken any medications that may affect BP (i.e. phenylephrine). However, we had no access to information regarding medications taken regularly, doses or type.

Normotension was classified according to recent hypertension guidelines as optimal blood pressure $(<120 \mathrm{mmHg}$ for systolic and $<80 \mathrm{mmHg}$ for diastolic), normal blood pressure (120-129 $\mathrm{mmHg}$ for systolic and/or $80-84 \mathrm{mmHg}$ for diastolic), and high normal blood pressure $(130-139 \mathrm{mmHg}$ for systolic and/or 85-89 $\mathrm{mmHg}$ for diastolic), while hypertension was defined as blood pressure $>140 \mathrm{mmHg}$ for systolic and/or $>90 \mathrm{mmHg}$ for diastolic blood pressure [12].

Levels of blood total cholesterol, triglycerides, high density lipoproteins (HDL), glucose, SGPT, SGOT and uric acid were also recorded from medical files, from the most recent blood tests. Since pilots undergo frequent blood analyses, the latest results were no more than three months old. Pilots who's flight service was not continuous (i.e. suspension, hospitalization etc.) were excluded from the study, however, none of the participants in the present study was excluded.

\section{RESULTS}

Fighter pilots' mean age in the present study was 39.1 years old $( \pm 7.9 y)$ and had flown for 2872.6 hours $( \pm 1959.6$ h). The mean systolic blood pressure (SBP) was 117.5 $\mathrm{mmHg}( \pm 7.7 \mathrm{mmHg})$ and the mean diastolic blood pressure (DBP) was $77.0 \mathrm{mmHg}( \pm 7.9 \mathrm{mmHg})$. Among the pilots, $200(66.7 \%)$ presented optimal BP values, $80(26.7 \%)$ had normal BP values and the remaining 20 (6.6\%) had high normal BP values. Most of the pilots were married $(83.0 \%)$, 12 were single (12\%) and there were 5 widowers (1.7\%).

Pilots were in service for 18.2 years in average $( \pm 6.2 \mathrm{y})$, had a mean body mass index (BMI) of $25.3( \pm 4.1)$, their blood glucose level was in average $89.7 \mathrm{mg} / \mathrm{dL}( \pm 8.7)$. Also, their mean blood total cholesterol value was $184.1 \mathrm{mg} / \mathrm{dL}$ $( \pm 35.4 \mathrm{mg} / \mathrm{dL})$, HDL mean value was $52.0 \mathrm{mg} / \mathrm{dL}( \pm 12.7$ $\mathrm{mg} / \mathrm{dL})$ and triglycerides mean value was $97.9 \mathrm{mg} / \mathrm{dL}( \pm 41.7$ $\mathrm{mg} / \mathrm{dL})$.

Half of the participants said they perceived their financial status as "good" $(50.7 \%), 42 \%$ found it "moderate" and 8 pilots think it was "bad". The majority of the pilots $(66.9 \%)$ reported exercising up to two times weekly, some of them (21.1\%) more than twice a week, while a small portion
$(12 \%)$ reported they didn't exercise at all. Participants mentioned they were exercising for a mean period of 12.0 years $( \pm 7.6 y)$ and most of them $(62.1 \%)$ preferred exercising outdoors in contrast to indoors structured gyms (37.9\%).

Very few pilots $(5.6 \%)$ reported employing only anaerobic exercises during work-out, more than half $(52.4 \%)$ used aerobic exercises and the remaining (42\%) said they used both aerobic and anaerobic exercises. Pilots were asked to state the main reason for exercising and they said it was a way of life since puberty $(43.1 \%)$ or owing to professional requirements $(43.5 \%)$. The remaining $(13.5 \%)$ said they exercised for health reasons.

Younger pilots seemed to prefer working-out in a gym $\left(r_{s}=-0.286, \quad p<0.01\right)$ using aerobic exercises $\left(r_{s}=-0.160\right.$, $\mathrm{p}<0.01)$. Also body mass index (BMI) was found to be negatively associated with exercise intensity $\left(r_{s}=-0.277, p<0.01\right)$ (self-reported exercise intensity answers included four choices: not at all, rarely, up to 2 times per week and more than 2 times per week). More frequent exercising was associated with lower blood glucose levels $\left(r_{s}=-0.239, p<0.001\right)$, blood uric acid levels $\left(r_{s}=-0.258, p<0.001\right)$, blood cholesterol levels $\left(r_{s}=-0.156, p<0.001\right)$, blood triglycerides levels $\left(\mathrm{r}_{\mathrm{s}}=-0.243, \mathrm{p}<0.001\right)$ and blood SGOT and SGPT levels $\left(r_{s}=-0.203, p<0.001\right.$ and $r_{s}=-0.210, p<0.001$, respectively $)$.

Almost one-third of the participants reported they were smoking (31.7\%). Among people who were smoking $(n=94)$, $33(35.1 \%)$ smoked up to 5 cigarettes daily, 40 smoked five to twenty cigarettes $(42.6 \%), 14$ smoked twenty to thirty $(14.9 \%)$ and seven $(7.4 \%)$ more than 30 cigarettes/day. In average, these pilots were smoking for 4.1 years $( \pm 7.9)$ and the main reason for starting smoking was by chance $(39.1 \%)$. Fifty four pilots reported quitting smoking either for preventive reasons $(n=39,66.1 \%)$ or for health reasons $(28.8 \%)$.

With regard to dietary habits (Table 1), nearly all participants reported they consumed olive oil on daily basis (96.3\%), while their weekly consumption amounted from 20 to $30 \mathrm{ml}(68 \%)$. Most of the participants $(n=190,63.3 \%)$ didn't consume alcohol. Those who did, mostly reported they consumed 1-2 glasses of wine $(n=96,87.3 \%)$. However, most of the pilots $(n=258,86 \%)$ consumed coffee with the majority drinking one cup of coffee every day $(n=191,74 \%)$, while only 4 pilots drink more than 4 cups of coffee on daily basis (1.6\%). People who reported consuming higher amounts of olive oil on weekly basis had higher blood HDL values $\left(r_{s}=0.119, p<0.05\right)$ and increased reported exercise intensity $\left(r_{s}=0.132, p<0.05\right)$.

Mean SBP was positively and significantly associated with age $\left(\mathrm{r}_{\mathrm{s}}=0.191, \mathrm{p}<0.01\right)$, flight hours $\left(\mathrm{r}_{\mathrm{s}}=0.211, \mathrm{p}<0.01\right)$, BMI $\left(r_{s}=0.205, p<0.01\right)$, alcohol consumption $\left(r_{s}=0.202\right.$, $\mathrm{p}<0.05)$, blood glucose levels $\left(\mathrm{r}_{\mathrm{s}}=0.154, \mathrm{p}<0.01\right)$, blood uric acid levels $\left(r_{s}=0.216, p<0.01\right)$, total cholesterol levels $\left(r_{s}=0.164, p<0.01\right)$, blood SGOT and SGPT levels $\left(r_{s}=0.125\right.$, $\mathrm{p}<0.05$ and $\mathrm{r}_{\mathrm{s}}=0.182, \mathrm{p}<0.05$, respectively) and negatively with self-reported exercise intensity $\left(\mathrm{r}_{\mathrm{s}}=-0.316, \mathrm{p}<0.01\right)$, blood HDL levels $\left(\mathrm{r}_{\mathrm{s}}=-0.215, \mathrm{p}<0.01\right)$.

Age was highly and positively associated with flight hours $\left(\mathrm{r}_{\mathrm{s}}=0.883, \mathrm{p}<0.001\right)$ and slightly with blood glucose levels $\left(\mathrm{r}_{\mathrm{s}}=0.122, \mathrm{p}<0.05\right)$, blood uric acid levels $\left(\mathrm{r}_{\mathrm{s}}=0.163\right.$, $\mathrm{p}<0.01)$ and blood cholesterol levels $\left(\mathrm{r}_{\mathrm{s}}=0.193, \mathrm{p}<0.01\right)$. 
Table 1. Participants' dietary habits.

\begin{tabular}{|c|c|c|c|c|c|c|}
\hline $\begin{array}{c}\text { How many times } \\
\text { do you consume }\end{array}$ & $\begin{array}{c}\text { Meat (portions on } \\
\text { weekly basis) }\end{array}$ & $\begin{array}{c}\text { Vegetables (portions } \\
\text { on weekly basis) }\end{array}$ & $\begin{array}{c}\text { Fish (portions on } \\
\text { weekly basis) }\end{array}$ & $\begin{array}{c}\text { Sweets (items on } \\
\text { weekly basis) }\end{array}$ & $\begin{array}{c}\text { Fruits (items on } \\
\text { daily basis) }\end{array}$ & $\begin{array}{c}\text { Fast-food (portions } \\
\text { on weekly basis) }\end{array}$ \\
\hline \hline Not at all & $0.7 \%$ & $6.4 \%$ & $7 \%$ & $28.4 \%$ & $9.3 \%$ & $80.3 \%$ \\
\hline $\begin{array}{c}1-2 \text { items or } \\
\text { portions }\end{array}$ & $61.3 \%$ & $62.5 \%$ & $86.7 \%$ & $52.2 \%$ & $63.7 \%$ & $14 \%$ \\
\hline $\begin{array}{c}3-5 \text { items or } \\
\text { portions }\end{array}$ & $34.3 \%$ & $27.4 \%$ & $6.3 \%$ & $15.6 \%$ & $25.7 \%$ & $3.4 \%$ \\
\hline $\begin{array}{c}\text { More than } 5 \text { items } \\
\text { or portions }\end{array}$ & $3.7 \%$ & $3.7 \%$ & - & $3.8 \%$ & $1.3 \%$ & $2.3 \%$ \\
\hline
\end{tabular}

A multivariate linear regression analysis was also performed to examine factors that may contribute to increased mean systolic blood pressure values. Factors were inserted hierarchically one by one in each block of the model. Initially, we searched for cases that might exert undue influence to our model. Therefore, we examined Cook's and Mahalanobis' distances and leverage values. There wasn't any case having a Cook's distance over 0.3 meaning there weren't any cases with extreme values [13]. Also, there wasn't any Mahalanobis' distance over 10.0, which means there weren't any cases differing significantly from mean predicted values [14]. Leverage values didn't exceed more than three times the one of mean predicted value $(<0.05)$ [15].

Standardized DFBeta and DFFit values didn't deviate from predicted values. Covariance ratio ranged within 0.95 and 1.05 as proposed by Belsey, Kuh \& Welsch's calculations [16]. Multicollinearity between variables was examined through Variance Inflation Factor (VIF) and Tolerance tests. The former yielded values around 1 and a mean VIF value of 1.115 , indicating there wasn't any significantly high association between predictive variables $[17,18]$. Tolerance values were all above the proposed 0.2 threshold. The DurbinWatson test was 1.657 , a value within the proposed range of 1 to 3 . In the final model (Table 2), four contributing factors were retained: BMI, flight hours, HDL value and reported exercise intensity level. Final coefficient of multiple correlation $\mathrm{R}$ was $0.507\left(\mathrm{R}^{2}=0.257\right)$.

According to model's results, systolic blood pressure can be predicted by the following equation: $\mathrm{SBP}=101.9+$ $(0.876 \times$ BMI $)+(0.001 \times$ Flight Hours $)+(-0.129 \times$ HDL $)+$ (-1.57 x Exercise Intensity).

\section{DISCUSSION}

Our study revealed that Greek military jet pilots have normal blood pressure levels; of note, two-thirds of jet pilots present optimal blood pressure levels. Factors affecting systolic BP levels were body mass index, flight hours, HDL values and exercise intensity. Most pilots were exercising up to two times weekly $(66.9 \%)$, while some didn't exercise at all $(12 \%)$.

As mentioned above, flight hours were associated with SBP $\left(\mathrm{r}_{\mathrm{s}}=0.211, \mathrm{p}<0.01\right)$, in accordance with Tomei et al. findings [19]. They reported strong associations between flight hours and both systolic and diastolic BP (group A-turboprop planes-systolic BP: $\mathrm{r}=0.97, \mathrm{p}=0.003$, diastolic
BP: $\mathrm{r}=0.98, \mathrm{p}=0.003$ ) (group B-jet planes-systolic BP: $\mathrm{r}=0.86, \mathrm{p}=0.025$; diastolic BP: $\mathrm{r}=0.76, \mathrm{p}=0.005$ ). They didn't find any association between flight hours and electrocardiographic abnormalities.

Pizzi et al. [20], investigated lifestyle factors of British pilots and air-traffic controllers with 21,376 people allowing access to their electronic records containing various data and 11,234 people also filled-in questionnaires and authors compared them with corresponding data from general population. They found that $3.8 \%$ of participating men were overweight. Median SBP and DBP were $126 \mathrm{mmHg}$ and $78 \mathrm{mmHg}$, respectively. They also reported that active smokers amounted to $6 \%$ and they smoked, in average, 15.3 cigarettes daily. Also, pilots reported they regularly consumed alcohol (94.1\%, 5 wine glasses/week), exercised regularly $(89.1 \%)$ for 24 years (median). Hypertension was found in $15 \%$ of the participants. Their findings are statistically, significantly lower compared to general population. In our study, median SBP and DBP were lower $(117 \mathrm{mmHg}$ and $77 \mathrm{mmHg}$, respectively), while smokers were more $(31.7 \%)$. Pilots consume less frequently alcohol $(36.7 \%), 88 \%$ exercise more than once weekly for 12.2 years, in average.

Bisseliches et al. [21], conducted a study in personnel working for Air-France airlines. Among 7000 participants, (3,223 ground personnel, 3,129 flight attendants, 511 pilots and co-pilots) they found 150 hypertensives $(2.14 \%)$, while ground personnel had significantly higher proportion of hypertension compared to pilots' group.

According to another study by Chimonas et al. [22], Greek air-force pilots had a mean daily intake of 3,003 $( \pm 1,242)$ calories. Pilots' mean age was 30 years $( \pm 9 y)$ and $36 \%$ were overweight (BMI $>25), 53.4 \%$ had blood HDL levels $<40 \mathrm{mg}$ and mean blood glucose levels of $93( \pm 7.6)$ $\mathrm{mg} / \mathrm{dl}$. Compared to their study, pilots in the present study are slightly more overweight. However, increased BMI values may be related to higher muscular mass. Also, only $8 \%$ of pilots in the present study presented blood HDL of less than $40 \mathrm{mg} / \mathrm{dl}$.

\section{STUDY LIMITATIONS}

Due to study's design, we weren't able to document any new cases of hypertension. However, no abnormal BP value was recorded. A substantial limitation in the present study was the fact that we had to omit several items from the original questionnaire (i.e. information regarding pilots' medical 
Table 2. Multivariate linear regression analysis: Model summary.

\begin{tabular}{|c|c|c|c|c|c|c|c|c|c|c|}
\hline \multicolumn{11}{|c|}{ Model Summary ${ }^{\mathrm{e}}$} \\
\hline Model & $\mathbf{R}$ & R Square & Adjusted R Square & Std. Error of the Estimate & R Square Change & F Change & df 1 & df 2 & Sig. F Change & Durbin-Watson \\
\hline 1 & $0.347^{\mathrm{a}}$ & 0.120 & 0.117 & 5.63716 & 0.120 & 40.733 & 1 & 298 & 0.000 & \\
\hline 2 & $0.412^{\mathrm{b}}$ & 0.170 & 0.164 & 5.48507 & 0.050 & 17.754 & 1 & 297 & 0.000 & \\
\hline 4 & $0.507^{\mathrm{d}}$ & 0.257 & 0.247 & 5.20653 & 0.031 & 12.318 & 1 & 295 & 0.000 & 1.657 \\
\hline \multicolumn{11}{|c|}{ a. Predictors: (Constant), Body Mass Index } \\
\hline \multicolumn{11}{|c|}{ b. Predictors: (Constant), BMI, Flight hours } \\
\hline
\end{tabular}

history, intake of medicines, etc.) that relevant military authorities characterized as sensitive and could not be included in data collection. Such factors could be associated with increased BP values. Nonetheless, since there wasn't any abnormal BP value recorded, the contribution of these factors could have been limited.

\section{CONCLUSION}

In the area of military air-forces and, to a corresponding extent, in civil aviation, failure of inanimate materials may have fatal consequences. Similarly, no omission and mistakes are allowed on the part of the working personnel. Consequently, the excellent physical, mental and psychological condition of pilots is practically synonymous to the positive outcome of each flight.

Although safety protocols have been made and implemented and pilots undergo extensive health examinations and monitoring, accidents are inevitable. A division of RAF conducted a study on 1,000 accidents involving aircrafts and concluded that a pre-existing disease had been the cause or the main contributing factor in 34 accidents, specifically 6 (among 407) in the military (1.5\%), 4 (among 114) in commercial flights $(3.5 \%), 16$ (among 375$)$ in general aviation $(4.3 \%)$ and 8 (among 67 ) in gliders $(8.3 \%)$. In most of them (22) cardiovascular anatomic damages were confirmed [23]. Military air-force accidents had the lowest incidence $(1.5 \%$ vs $8.3 \%$ in gliders). It should be noted that in that study there were included only cases of severe or moderate diseases, allowing, thus, an underestimation of pilots' overall health condition.

In the present study, pilots' BP values were all within normal range. This finding is encouraging and may reflect pilots' continuous efforts to maintain a healthy way of living. Similar BP values have also been reported in the literature $[10,11]$. On the other hand, there were some overweight pilots and smokers, while, few reported not exercising.

Therefore, there is a need to encourage and possibly enhance training programs that are already in use for physical exercise. Smoking cessation interventions should also be employed and health care personnel could stress the benefits of a healthier diet. Additionally, pre-entry examinations in military pilot schools in Greece could be enriched with ultrasound test in order to detect any latent abnormalities early.

Finally, the present study also confirms the healthyworker phenomenon [20, 24, 25], according to which, people employed in positions of increased physical and mental challenges and undergo frequent medical examinations, present a substantially better health condition compared to general population.

\section{CONFLICT OF INTEREST}

The authors confirm that this article content has no conflict of interest.

\section{ACKNOWLEDGEMENTS}

Declared none.

\section{REFERENCES}

[1] Skliros EA, Papaioannou I, Sotiropoulos A, Giannakaki G, Milingou M, Lionis C. A high level of awareness but a poor control of hypertension among elderly Greeks: the Nemea primary care study. J Hum Hypertens 2002; 16: 285-7.

[2] Stergiou GS, Thomopoulou GC, Skeva II, Mountokalakis TD. Prevalence, awareness, treatment and control of hypertension in Greece: the Didima study. Am J Hypertens 1999; 12: 959-65.

[3] Panagiotakos DB, Pitsavos C, Chrysohoou C, Skoumas I, Stefanadis C. Prevalence and five-year incidence (2001-2006) of cardiovascular disease risk factors in a Greek sample: the ATTICA study. Hellenic J Cardiol 2009; 50: 388-95.

[4] Panagiotakos DB, Pitsavos CH, Chrysopoulou C, et al. Status and management of hypertension in Greece: role of the adoption of a Mediterranean diet: the Attica study. J Hypertens 2003; 21: 1483-9.

[5] Panagiotakos DB, Pitsavos C, Chrysohoou C, Stefanadis C, Toutouzas P. Risk stratification of coronary heart disease in Greece: final results from the CARDIO2000 Epidemiological Study. Prev Med 2002; 35: 548-56.

[6] Psaltopoulou T, Orfanos P, Naska A, Lenas D, Trichopoulos D, Trichopoulou A. Prevalence, awareness, treatment and control of 
hypertension in a general population sample of 26,913 adults in the Greek EPIC study. Int J Epidemiol 2004; 33: 1345-52.

[7] Silverman D, Gendreau M. Medical issues associated with commercial flights. Lancet 2009; 373: 2067-77.

[8] Mieske K, Flaherty G, O'Brien T. Journeys to high altitude-Risks and recommendations for travelers with pre-existing medical conditions. J Travel Med 2009; 17: 48-62.

[9] Froom P, Gross M, Barzilav J, Forecast DF, Margaliot S, Benbassat J. Systolic blood pressure in fighter pilots after 12-15 years of service. Aviat Space Environ Med 1986; 57: 367-9.

[10] Grossman A, Wand O, Harpaz D, Prokupetz A, Assa A. Acceleration forces and cardiac and aortic indexes in jet fighter pilots. Aviat Space Environ Med 2011; 82: 901-3.

[11] Assa A, Prokupetz A, Wand O, Harpaz O, Grossman A. Echocardiographic evaluation and aortic indexes in aviators exposed to acceleration forces. J Am Soc Echocardiogr 2011; 24: 1163-7.

[12] Mancia G, Fagard R, Narkiewicz K, et al. 2013 ESH/ESC Guidelines for the management of arterial hypertension. J Hypertens 2013; 31: 1281-357.

[13] Cook RD, Wiesberg S, Eds. Residuals and influence in regression. New York: Chapman and Hall 1982.

[14] Barnett V, Lewis T, Eds. Outliers in statistical data. New York: Wiley 1978.

[15] Stevens JP, Ed. Applied multivariate statistics for the social sciences. $2^{\text {nd }}$ ed. Hillsdale, NJ: Erlbaum 1992.

[16] Belsey DA, Kuh E, Welsch R, Eds. Regression diagnostics: identifying influential data and sources of collinearity. New York: Wiley 1980.
[17] Myers R, Ed. Classical and modern regression with applications. 2nd ed. Boston, MA: Duxbury 1990.

[18] Bowerman BL, O'Conell RT, Eds. Linear statistical models: an applied approach. 2nd ed. Belmont, CA: Duxbury 1990.

[19] Tomei F, DeSio S, Tomao E, et al. Occupational exposure to noise and hypertension in pilots. Int J Environ Health Res 2005; 15: 99106

[20] Pizzi C, Evans SA, De Stavola BL, Evans A, Clemens F, Dos Santos Silva I. Lifestyle of UK commercial aircrew relative to traffic controllers and the general population. Aviat Space Environ Med 2008; 79: 964-74.

[21] Bisseliches F, Lanoote M, Moussu C, Montagne C. Hypertension: a survey of 7000 Air-France employees. J Hum Hypertens 1990; 4: 326-9.

[22] Chimonas ET, Sialvera TE, Zampelas A. Dietary habits in fighter pilots of Hellenic Air Force. Hell Aerosp Med 2004; 1: 8-10.

[23] Cullen SA. Aviation Pathology. In: Ernsting J, Nicholson AN, Rainford DJ, Eds. Aviation Medicine. 3rd ed. 2003.

[24] Houston S, Mitchell S, Evans S. Prevalence of cardiovascular disease risk factors among UK commercial pilots. Eur J Cardiovasc Prev Rehabil 2011; 18: 510-7.

[25] Ekstrand K, Bostrom PA, Arborelius M, Nilsson JA, Lindell SE. Cardiovascular risk factors in commercial flight aircrew officers compared with those in the general population. Angiology 1996; 47: 1089-94.

(C) Platsas et al.; Licensee Bentham Open.

This is an open access article licensed under the terms of the Creative Commons Attribution Non-Commercial License (http://creativecommons.org/licenses/by-nc/3.0/) which permits unrestricted, non-commercial use, distribution and reproduction in any medium, provided the work is properly cited. 